\title{
Problems of phytoimmunity of grain crops in the Euro-Northeast of the Russian Federation and ways their solution
}

\author{
Tatyana Sheshegova, and Lucia Shchekleina* \\ Federal Agrarian Scientific Center of the Northeast named after N.V. Rudnitsky, city of Kirov, \\ Russian Federation
}

\begin{abstract}
Breeding of grain crops for phytoimmunity in the FSBSU FASC of the Northeast is carried out in the conditions of natural and artificial epiphytotics. Every year, more than 1000 samples of winter rye, spring soft wheat, barley and oats of their own breeding and from the VIR collection are studied. In winter rye, studies are conducted on snow mold, root rot, powdery mildew, brown and stem rust, septoria blight, fusarium head blight, and ergot; in spring wheat - on root rot, septoria blight, fusarium head blight, powdery mildew, brown rust, loose smut; in barley on root rot, net, dark brown blotch and stripe disease, loose smut; in oats on red-brown blotch, root rot, crown rust, panicle fusarium and loose smut. Resistant samples detected on infectious backgrounds will be included in the breeding process as sources of the trait. With the participation of source genes, new varieties of winter rye were created, Snezhana, Grefinya, and others, which are being studied at different breeding stages. Long-term studies (2014-2020) on infectious and provocative backgrounds among the breeding material of the FASC of the Northeast and collection samples of spring soft wheat, oats, barley revealed sources of nonspecific resistance (6-9 points). They are used in crossbreeding programs with the best varieties to obtain high-yielding and resistant to biotic stressors hybrids that are being studied at different breeding stages.
\end{abstract}

\section{Introduction}

Improving the efficiency of agricultural production at the present stage is impossible without solving the problems of plant protection from diseases. Nevertheless, even the targeted use of chemicals only temporarily improves the situation. Agricultural production needs varieties having different mechanisms and types of resistance, capable of providing long-term protection from epiphytotic dangerous diseases. Crop rotations, agricultural cultivation techniques and resistant varieties have served as guarantors of a successful phytosanitary situation. Through immune and resistant varieties, there are wide opportunities for managing the number and harmfulness of pathogenic microorganisms, which partially solves the problem of obtaining a high yield of environmentally friendly products [1.2].

\footnotetext{
${ }^{*}$ Corresponding author: immunitet@fanc-sv.ru
} 
The natural and geographical conditions of the Kirov region are unique in terms of the duration of the winter period (160-180 days) and the snow abundance $(60-90 \mathrm{~cm})$, and are also characterized by a reduced temperature regime in the summer and winter months. The specificity of the agro-climatic conditions of the region also lies in the relatively weak biological activity and low soil fertility: humus - 2.0-2.3\%, mobile phosphorus - on average $119 \mathrm{mg} / \mathrm{kg}$, exchange potassium - $121 \mathrm{mg} / \mathrm{kg}$, $\mathrm{pH}$ of the soil medium - mainly 5.0 units. All these factors reduce the adaptive properties of agricultural plants and their resistance to a complex of unfavorable abiotic factors, contribute to the increased development and harmfulness of pathogens of fungal and bacterial diseases.

In the Euro-Northeast of the Russian Federation, grain crops have historically developed their own specific pathocomplexes. An economically significant danger on winter rye is represented by: snow mold and root rot, which manifest themselves annually to one degree or another; local development of sclerotinia with a very high (up to $70 \%$ ) harmfulness; then powdery mildew, types of rust, septoria and fusarium head blight [3. 4]. On spring soft wheat, there is an annual manifestation of septoria of leaves and ears, brown rust, root rot and fusarium head blight. Barley is annually affected by spotting of fungal etiology (striped, net, leaf, dark brown) and root rot. On oats, the most common is red-brown spotting of bacterial and fungal etiology, as well as crown rust and fusarium panicle. In some years, local outbreaks of smut diseases are observed on spring grain crops [5], and ergot is currently of economic importance on winter rye and spring soft wheat [6].

Immunological research in the FSBSU FASC of the Northeast on grain crops has a long history, the beginning of which dates back to the 80-90-ies of the last century. In 2004, the Laboratory of immunity and plant protection was established, which continues research on the theory and practice of phytoimmunity. Considering regional phytosanitary problems, the main tasks are the following: regional monitoring of the phytosanitary state of agricultural crops; study of the specific and intraspecific structure of local populations of pathogens to substantiate the composition of artificial infectious backgrounds; development and improvement of plant inoculation methods for an objective assessment of crop gene pools; identification and creation of sources and donors of resistance for breeding; development of technology for breeding varieties with different types and mechanisms of resistance to diseases.

\section{Material and methods}

The breeding and immunological studies are conducted against the background of natural or artificial epiphytotics. For this purpose, our laboratory has a working collection that includes more than 50 strains of phytopathogenic microorganisms. The approximate scheme of immunological studies involves the following stages:

- step-by-step screening of the gene pools of grain crops in the cameral and in the field conditions with artificial inoculation of plants;

- recurrent selection of stable and highly productive forms in the field on artificial infectious backgrounds;

- crosses (saturating, stepwise, convergent) of breeding valuable samples with genetic sources of resistance.

When modeling phytopathocenoses, septoria and helminthosporiosis spottings, types of rust and loose smut, well-known methods are used [7-12], snow mold, root rot, fusarium head blight, ergot - original ones $[13,14]$. When creating source genes, we focus on nonspecific stability. Such forms are usually more adaptive and adapted to specific regional agroecological conditions. The research was carried out within the framework of the State Task on the following topics: No. 0767-2019-0093 and No. 0767-2019-0095. 


\section{Results and discussion}

It was found that fusarium fungi with a predominance of $F$. culmorum(W.G.Sm.) Sacc, $F$. oxysporum Schlecht, $F$. sporotrichioides Sherb dominate among the pathogens of root rot in winter rye, oats and spring soft wheat. The pathocomplex of root infections of barley is dominated by Bipolaris sorokiniana (Sacc.) Shoem. in community with F. culmorum and $F$. oxysporum. Therefore, when creating an infectious background, an "artificial" population is used, made up of pathogenic strains of these species. The main agent of fusarium head blight of rye and wheat is $F$. culmorum; in wet years, there are species $F$. avenaceum ( $\mathrm{Fr}$.) Sacc. and $F$. sporotrichoides. However, given the highest frequency of $F$. culmorum, inoculum mainly includes strains of this species [3. 14].

The study of the racial composition of the Kirov population of Puccinia coronata was carried out on 17 isogenic lines of the Pendec variety [16]. The Pc62 and Pc63 genes were the most effective in protecting against crown rust. In the studied population of the pathogen, all clones were avirulent to lines with these genes. The occurrence frequency of isolates virulent to the Pc55, Pc58, Pc60, Pc61 genes has significantly increased, and the occurrence of the Pc48 and Pc39 genes has decreased. The identified virulence genes in individual isolates were found in different combinations. Clones that are avirulent to all the lines used $(21.9 \%)$ and virulent to $1-2$ lines $(14.6 \%)$ were identified with the highest frequency. The greatest danger to plants is represented by pathotypes containing the maximum number of virulence alleles -7 or 8 , although there were a small number of such clones $(4.9 \%)$.

In winter rye, the scientific provisions of one of the most difficult areas of this crop breeding have been developed - the creation of short-stemmed varieties that are resistant to snow mold, root rot and fusarium head blight [15]. Using this technique, multiple selections of highly resistant biotypes were carried out on artificial infectious backgrounds of pathogens. After their directed re-pollination, effective sources of resistance to these diseases were obtained, with the use of which high-yielding and resistant to fusarium diseases varieties Snezhana (2005) and Grafinya (2016) were created. It was entered into the State Register of Breeding Achievements of the Russian Federation and a patent was obtained for a new variety of Rada, characterized by relatively high immunological indicators on infectious backgrounds: resistance to snow mold (regrowth after $80 \%$ lesion), moderate resistance to root rot (the development of the disease is about $18.0 \%$ ) and ergot (10.0\% lesion). A new variety Rumba, resistant to snow mold and relatively weakly affected by ergot, has been prepared for transfer. New populations Fantasy and Harmony, created with the participation of sources of resistance to fusarium head blight and ergot, are being tested competitively.

In recent years, due to a number of reasons, the problem of ergot has become acute. Currently, there are no targeted breeding programs to increase resistance to the disease, there is insufficient information about the state of the gene pools of grain crops for resistance, since infectious backgrounds are practically not used, the mechanisms of resistance to this disease are not clear. With artificial inoculation, we tested more than 100 varieties of winter rye. There were no immune forms, and in 10 varieties the lesion varied from 5.8 to $33.0 \%$, the content of sclerotia in the grain - from 0.3 to $1.4 \%$ (in the indicator variety, respectively, $100 \%$ and $37.0 \%$ ). Among them there are new populations of Rumba, Symphoniya, Perepel, Graphit and Garmoniya. It should be noted that the breeding program for resistance to ergot must necessarily contain a nursery of artificial infection, since the influence of environmental factors on the pathological process is very large $[17,14]$. To enhance the development or provocation of the disease, the sowing should be kind of sparse. During the selection, attention should be paid not only to the immunological signs (lesion and its intensity), but also to the nature of the genotype flowering and the ear grain 
content in the selected biotypes.

At the experimental base of the FSBSI IBFM RAS n.a. G.K. Skryabin, the composition and content of ergoalkaloids (EA) in the sclerotia of the Kirov population of the fungus $C$. purpurea was analyzed. The EA composition was the same and consisted of ergocrystine, ergotamine and its stereoisomer - ergotaminine [18]. The amount of EA varied from 0 to $0.36 \%$ of their weight, but they were not detected in 9 new rye populations of the breeding of the FASC of the Northeast. A weak negative relationship $(r=-0.46)$ was found between the mass of one sclerotium and the EA accumulation. Information about the EA level is important for the search for immunologically and selectively valuable genotypes that combine resistance to ergot lesion and to the EA accumulation. This trait distinguishes the new populations of Rumba, Symphoniya and Garmoniya.

The new varieties of winter rye identified in recent years can be recommended as reliable sources of complex resistance to fungal diseases (Table 1).

Table 1. Sources of resistance to fungal diseases among the varieties FASC of the Northeast breeding (provocative and infectious backgrounds, 2016-2020).

\begin{tabular}{|c|c|c|c|c|c|c|c|}
\hline \multirow[b]{2}{*}{ 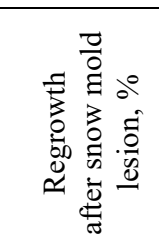 } & \multicolumn{6}{|c|}{ Degree of lesion, $\%$} & \multirow[b]{2}{*}{ 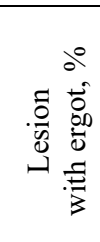 } \\
\hline & 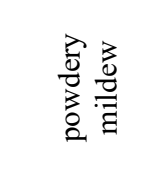 & 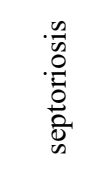 & 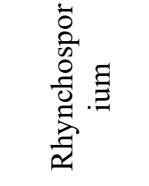 & 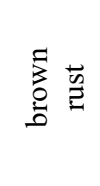 & 兽 & $\stackrel{0}{\circ} \stackrel{0}{0}$ & \\
\hline 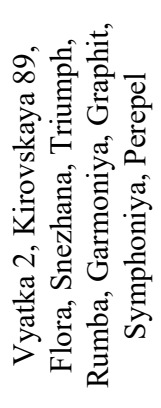 & 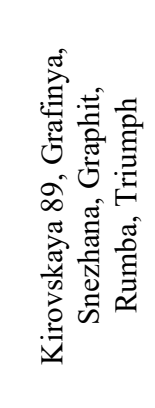 & 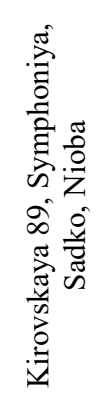 & 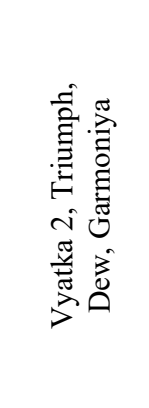 & 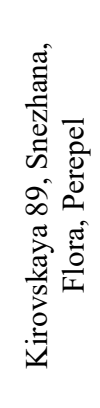 & 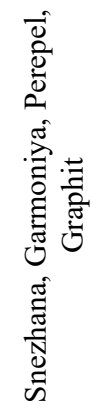 & 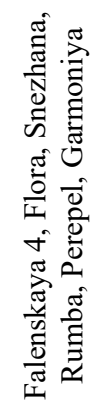 & 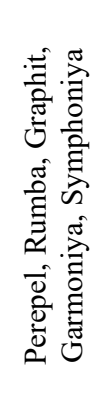 \\
\hline \multicolumn{8}{|c|}{ Level of phenotypic manifestation of the trait in resistant varieties: } \\
\hline $70.0 \ldots 100$ & $10.0 \ldots 15.0$ & $\begin{array}{c}10.0 \ldots \\
15.0\end{array}$ & $6.7 \ldots 15.0$ & $\begin{array}{c}10.0 \ldots \\
20.0\end{array}$ & $\begin{array}{l}8.3 \ldots \\
20.0\end{array}$ & $\begin{array}{c}3.5 \ldots \\
20.0\end{array}$ & $\begin{array}{c}6.3 \ldots \\
14.2 \\
\end{array}$ \\
\hline \multicolumn{8}{|c|}{ Level of manifestation of the trait in indicator varieties: } \\
\hline 20.0 & 52.0 & 44.0 & 24.0 & 46.7 & 45.0 & 45.8 & 78.5 \\
\hline
\end{tabular}

Long-term studies (2014-2020) on infectious and provocative backgrounds among the breeding material of the FASC of the Northeast and collection samples of spring soft wheat, oats, barley revealed sources of nonspecific resistance (6-9 points). They are used in crossbreeding programs with the best varieties to obtain high-yielding and resistant to biotic stressors hybrids that are being studied at different breeding stages. Among them, the following gene pool can be noted:

- barley, resistant to root rots - 66-08, 105-09, 33-11, 93-13, 94-13, 209-14, 54-14, 11513, 210-14, 212-14, 211-14: to the stripe disease - 217-08, 121-08, Forward, 33-11, 38310, Bezenchukskiy 3 (Russia), Surpriz (Ukraine), Calcul, Posada (Germany), Mie (Estonia), MAKBO (Australia), Patricia (France), the local k-5983 (Afghanistan), k-3506 (India), k-2929 and k-2930 (China), etc.; to net blotch - Forsazh, 150-08; Forward, 33-11, 472-08, 341-08, 515-08, 383-10, 126-13, 57-13, 93-13, 52-12, 40-13, 45-13, 168-12, Medikum 336, Ratnik (Russia), the local 1-3282 (Ethiopia), k-19095 (India), Ilek 34 
(Kazakhstan), 713 A, 696 C (Switzerland), etc.; to dark-brown spot - Forward, 66-08, 34108, 247-09, 105-09, 515-08, 33-11, 399-11, 363-11, 120-13, 121-13, 126-13, 116-13, $122-$ 13, 45-13, 57-13, 93-13, 94-13, 168-12, 288-12, Symphoniya (Ukraine), Danuta, Posada (Germany), Patricia (France), Haxby (USA), etc.;

- oats,_resistant to root rots - 2h09, 766h05, 407h06, 2h12o, 7h12o, 683h05,1h07, 325h12, 24h12o, 373h12, 52h11, 52h11, 325h12, 373h12, 46h14, 14h12o, 21h12o, 52h11, 154h13, 156h13; to red-brown spot - 2h09, 2h12o, 1h12o, 93h08, 407h06, 9h09, 207h07, 735h05, 7h12o, 2h10, 14h12o DARUNOK (Ukraine), POLOVETS (Altai Krai), POMOR (Kemerovo region), Mina (Bulgaria), MF9521-79 (USA), BOHUN (Poland), MALIN (Germany), ROCKY (Germany), WERVA (Germany); to fusarium - 93h08, 2h09, 378h08, 2h12o, 9h09, 3h10, 683h05, 41h04, 4h12o, 735h05, Taydon (Russia), MF9521-79 (USA), Taydon (Russia), PZS-LYM-04 (China), Gkzalon (Mongolia), Bay 15 (China), etc.;

- spring soft wheat, resistant to root rots - K-97, M-20, P-57, L-276, Oh-79, On-121, P122, P-103, P-57, S-103, S-84, S-129, T-97 T-79, I-28; to Septoria blotch - N-154, P-57, P63, T-97 R-98, T-99 T-100, S-84, S-122, T-66, T-79 T-140, T-141, Moscovskaya 35, Krasnoufimskaya 100, Tobolskaya, Omskaya 41, Ekada 70, Tulaykovskaya Nadezhda (Russia), Long Chun 8 (China), Epos, Xenos, Naxos (Germany), etc.; to powdery mildew Bazhenka, N-154, P-57, S-177, S-64, S-65, S-84 Moscow 35, 70 Ekada, Almata, Chernozemelsky 2,Tyumen 29, memory Leontiev, Catherine, khutoryanka (Russia), Long Chun 8 (China), Xenos (Germany) to brown rust - N-154, S-64, S-180, S-138, T-98, T100, Tulaikovskaya 10, Moscow 35 Almata, Uralosibirskaya, Omskaya 41, Khutoryanka, Tobolskaya (Russia), Chun Liao 2, Da 742, Hong Mai 5 (China), etc.; to fusarium head blight - S-64, S-65, S-54, S-122, S-138, T-97 T-98 T-99, T-140, I-80, 35 Moscovskaya (Russia), etc.; to ergot - Bazhenka, P-103, P-63, S-65, T-66, S-54, S-84, S-129.

\section{Conclusion}

The organization of selection and immunological studies on artificially infectious backgrounds made it possible to identify and create effective sources of grain crops that are resistant to one or more fungal diseases. With their use, new varieties of winter rye and promising breeding material of spring grain crops have been created, which are being studied according to a complex of traits at different breeding stages.

\section{References}

1. A.A. Zhuchenko, M.: Publishing house Agrorus 3, 958, (2009)

2. O.V. Solodukhina, V.D. Kobylyansky, Proceedings on applied botany, genetics and breeding 168, 79-89, (2011)

3. L.I. Kedrova, Kirov: NIISH of the Northeast, 158, (2000)

4. L.M. Shchekleina, Agrarian Science of the Euro-Northeast 21(2), 124-132 (2020)

5. T.K. Sheshegova, I. N. Schennikova, Bulletin of the Altai State Agrarian University 3 (173), 25-31 (2019)

6. L.M. Shchekleina, Agricultural Science of the Euro-Northeast 20 (2), 134-143 (2019)

7. M.F. Grigoriev, L., 60, (1976)

8. A.A. Benken, V.N. Khrustovskaya, Proceedings of the VIZR, 9-13 (1977)

9. N.A. Rodina, Z.G. Efremova, M., 79 (1986)

10. V.I. Krivchenko, D.V. Myagkova, A.E. Zhukova, A.P. Khokhlova, L., 109 (1987)

11. O.S. Petrova, O.S. Afanasenko, St. Petersburg: VIZR, 27 (2003) 
12. O.S. Afanasenko, Identified plant gene pool and breeding, 592-609 (St. Petersburg: VIR, 2005)

13. T.K. Sheshegova, L.I. Kedrova, Kirov, 30, (2003)

14. T.K. Sheshegova, L.M. Shchekleina, L.I. Kedrova, E.I. Utkina, Methodical manual, 27 (Kirov: FSBEI HE Vyatka State Agricultural Academy, 2018)

15. T.K. Sheshegova, Abstract diss. ... doctor of Biological Sciences, St. Petersburg, 39 (2002)

16. T.P. Gradoboeva, T.V. Lyskova, T.B. Lekomtseva, Proceedings of the All-Russian Conf. S.-Pb: VIZR, 120-122 (2008)

17. T. Miedaner, H.H. Geiger, Toxins, 7, 659-778 (2015)

18. T.K. Sheshegova, L.M. Shchekleina, V.P. Zhelifonova, T.V. Antipova, B.P. Baskunov, A.G. Kozlovsky A.G.' Mycology and phytopathology 53 (3), 177-182 (2019) 